\title{
STUDY OF STUDENT LEARNING APPROACH IN TWO DIFFERENT SUBJECTS ON THE SAME YEAR
}

\author{
N. Lajara, A. Pérez-de-Castro, M. Leiva-Brondo \\ Universitat Politècnica de València (SPAIN)
}

\begin{abstract}
Biggs' R-SPQ-2F questionnaire has been widely used since its release in 2001 to assess the student approach to learning, identifying two main approaches: Deep and Surface Approaches. The results of the questionnaire help to evaluate the teaching system as students' approach to learning depends, among other factors, on the current teaching context and therefore, it is not a fixed quality of the learner. Based on this, the approaches of 74 first-year students of the Degree in Biotechnology at Universitat Politècnica de València have been analysed under two different teaching frames: a first-term subject in Genetics and a second-term subject in Business Economics. Although some students maintain their approach to learning, differences between both subjects have been found significant for the main scales and most of the secondary ones, although not for language used as medium of instruction or gender. The item reliability analysis showed a high consistency for the main scales, but not for the secondary scales of the questionnaire. These data contribute to reinforce the theory that students stablish a learning approach according to the demands of the subject and context and modify their approach to learning.
\end{abstract}

Keywords: R-SPQ-2F; deep and surface approach; assessment; learning styles.

\section{INTRODUCTION}

Science and Health studies at University seek to develop a reflective, life-long learning and professional environment related learning students [1]-[3]. A deep approach to learning is necessary to reach these goals [4]. Student approach to learning can be divided in two different approaches: deep approach (DA) and surface approach (SA) [5]-[7]. This classification arise from the interest in the nature of student learning in higher education [8]. The student's approaches to learning (SAL) theory was initially developed by Marton and Säljö [9], [10], and their work was later continued by Entwistle [11], [12] and Biggs [13]. Assessment of how students learn can improve the outcomes of teaching [14]. Surface approach is characterized by the effort of the student to pass the course requirements, without intrinsic motivations [14]-[17], and normally memorizing is one of their main tools of learning [18]. Academic achievements are often negatively correlated with surface approach [19]. Factors that can make the student choose this approach are unclear: teaching goals, assessment system or workload have been proposed [13], [14], [20]. By the other side, deep approach is chosen by students with an intrinsic motivation that use strategies to learn and enjoy learning [14]-[16], [21] and it has shown positively correlation with academic success [19], [22]-[24].

Learning is not an isolated process and vary depending on the context and the requirements of the different disciplines [25]. For example Biggs [13] described a different approach to learning in Science and Arts students. A model with three steps (presage, process and product) was proposed by Biggs [26]. Several factors can affect student approach [8], [13], [27]. Some of the factors are personal and refer to the student, like gender, age, personality, social context, previous knowledge or skills [13], [19], [27]-[29]. Age and gender are two of the most important demographic variables [27], but for the gender factor different results arise from different studies [24], [28], [30]-[32]. An increment of deep approach has been observed related to the age of the student [29], [32]-[34], possibly because older students have more intrinsic motivation [35].

Contextual factors can include the curriculum of the degree, the type of studies, the discipline, the teaching methodology or the assessment system [13], [25], [27], [36]. Students' approach to learning can change in different subjects and years of a degree [3], [25], [37]-[39]. It is generally assumed that higher education promotes deep approach [3], [27], [40]. However, results of previous studies give different results depending on the context. For example, a decline of deep approach was observed between first-year and third-year students in some studies [13], [39], [41], [42]. Other studies showed that deep approach did not change [41], [43]-[45], while others showed a different behaviour with a decline in surface approach [46], [47]. This behaviour can be affected by teacher performance [33], [36], 
[48]-[53], but also by external factors and perceived factors. Perceived factors are those influenced by the student point of view [13], [25], [27], like workload, teaching system, clarity of goals, or the assessment system [27], [36], [49], [53]. As an example, students are able to change their approach to learning depending on the perception of course requirements [54].

Teaching should take into account student approach to choose teaching methodologies more appropriate [55], [56]. The assessment of student approach to learning can be used to modify teaching and learning environment [16], [57]. This could drive the student to a more deep approach, although is difficult to change their initial approach [53], [58]-[60]. Several tools can be used to measure student approach to learning [61]. Study Attitudes and Methods Revised Short Form (SAMS Short Form) [62], Inventory of Learning Process-Revised (ILP-R) [63], Revised Approaches to Studying Inventory (RASI) [64] modified in Approaches and Study Skills Inventory for Students (ASSIST) [65], [66], Approaches to Learning and Studying Inventory (ALSI) [12], Learning and Study Inventory Strategies (LASSI) [67], or Inventory of Learning Styles (ILS) [68] are some of the instruments developed. One of the most used is the Study Process Questionnaire (SPQ) developed by Biggs [13]. This questionnaire initially consisted of three dimensions: deep, surface and achieving, with two sub-dimensions (motive and strategy) each of them [13], [69]. However, the questionnaire was revised and its structure changed to only two factors (deep and surface) and two subscales (motive and strategy) in the Revised 2 factor version (R-SPQ2F) [5]. As stated previously, the questionnaire does not assess the student general approach to learning but specific responses to a particular subject or situation [5], [16], [70].

The R-SPQ-2F questionnaire has been translated to different languages [15], [56], [61], [71]-[73]. Moreover, the internal consistency of the R-SPQ-2F questionnaire has been evaluated [5], [74] and different models have been proposed with different association of the factors of the questionnaire, but a two factor structure is the most accepted [75], [76].

In the present study, the student approach to learning of the same students was assessed in two subjects, General Genetics and Biotechnology Business Economics, in year 2020-2021. Both subjects are from the first year of the Biotechnology degree, one in the winter term and the second in the spring term. To assess the student approach to learning, the R.SPQ-2F questionnaire was used at the beginning of each of the subjects. With the resulting data, the evolution of student approach to learning can be assessed in the student per basis in two different subjects of the same year and degree.

\section{METHODOLOGY}

Two subjects of the first year of the bachelor's degree in Biotechnology in 2020-21 were chosen for this study: General Genetics is a first-term subject with six ECTS (European Credits Transfer System), four corresponding to theory sessions ( 40 hours) and two of laboratory sessions ( 20 hours). The number of students enrolled was of 107. The other subject was Biotechnology Business Economics of the second term, with six ECTS, three of theory sessions ( 30 hours) and three of practical sessions (classroom and computer sessions). The number of students enrolled was of 103. Two groups were organized, one group with Spanish as language used for instruction and the other with English as language used for instruction. The teaching system was organized with theory sessions with different activities that later were experimented in the practical and computer sessions. The learning platform based in Sakai called PoliformaT was used to deliver all the materials and to perform assessment activities.

The R-SPQ-2F questionnaire developed by Biggs [5] was submitted to the students at the beginning of each of the subjects on-line through University learning platform Sakai-based PoliformaT. The original questionnaire was used for the English group while for the Spanish group a translation of the questionnaire was used [77]. Statgraphics Centurion XVII (Statpoint Technologies, Inc.) was used to analyse the results calculating correlations between factors and Cronbach's alpha values.

\section{RESULTS}

The rate of response of the students was high ( $83 \%$, ranging from $74 \%$ to $93 \%$ ) (Table 1 ). No significant differences in percentages of participation were observed regarding subject, language, or gender. Mean DA values were significantly higher than the SA values in both subjects, and this pattern was also observed when analysed considering language or gender (Table 1). 
Table 1. Number of students who answered the questionnaire by subject (General Genetics, GG, and Biotechnology Business Economics, BBE), language used as medium of instruction and, gender. Values (average and standard error) of the R-SPQ-2F questionnaire scales in the deep approach (DA), surface approach (SA), difference between DA and SA and null hypothesis DA-SA.

\begin{tabular}{|c|c|c|c|c|c|c|c|c|}
\hline & $\begin{array}{l}\text { No. answers } \\
\text { (\% enrolled) }\end{array}$ & $D A$ & & $S A$ & & $\begin{array}{c}\text { Difference } \\
\text { DA-SA }\end{array}$ & & $\begin{array}{c}\text { Null hypothesis } \\
\text { DA-SA }\end{array}$ \\
\hline \multicolumn{9}{|l|}{ Subject } \\
\hline GG & $99(0.93)$ & $3.41 \pm 0.05$ & $a^{1}$ & $1.79 \pm 0.04$ & $a$ & $1.62 \pm 0.07$ & $\mathrm{~b}$ & $* * *$ \\
\hline BBE & $76(0.74)$ & $3.27 \pm 0.06$ & a & $1.99 \pm 0.05$ & $\mathrm{~b}$ & $1.28 \pm 0.09$ & a & $* * *$ \\
\hline \multicolumn{9}{|l|}{ Language } \\
\hline Spanish & $105(0.78)$ & $3.33 \pm 0.05$ & $a$ & $1.91 \pm 0.04$ & $\mathrm{a}$ & $1.42 \pm 0.07$ & a & $* * *$ \\
\hline English & $70(0.92)$ & $3.38 \pm 0.07$ & $a$ & $1.83 \pm 0.05$ & $\mathrm{a}$ & $1.54 \pm 0.10$ & $a$ & $* * *$ \\
\hline GG Spanish & $63(0.90)$ & $3.33 \pm 0.06$ & $a$ & $1.82 \pm 0.05$ & $a$ & $1.51 \pm 0.09$ & $a$ & $* * *$ \\
\hline GG English & $36(0.97)$ & $3.54 \pm 0.09$ & $\mathrm{~b}$ & $1.74 \pm 0.06$ & $\mathrm{a}$ & $1.80 \pm 0.12$ & a & $* * *$ \\
\hline BBE Spanish & $42(0.66)$ & $3.32 \pm 0.08$ & $a$ & $2.03 \pm 0.07$ & $a$ & $1.29 \pm 0.12$ & $a$ & $* * *$ \\
\hline BBE English & $34(0.87)$ & $3.20 \pm 0.10$ & a & $1.93 \pm 0.08$ & $a$ & $1.27 \pm 0.15$ & $a$ & $* * *$ \\
\hline
\end{tabular}

Gender

\begin{tabular}{ccccccccc} 
Female & $115(0.84)$ & $3.35 \pm 0.05$ & a & $1.82 \pm 0.04$ & a & $1.53 \pm 0.08$ & a & $* * *$ \\
Male & $60(0.82)$ & $3.34 \pm 0.06$ & a & $1.99 \pm 0.04$ & b & $1.36 \pm 0.08$ & a & $* * *$ \\
\hline Total & $175(0.83)$ & $3.35 \pm 0.04$ & & $1.88 \pm 0.03$ & & $1.47 \pm 0.06$ & & $* * *$
\end{tabular}

${ }^{1}$ Different letters in the same column indicate significant differences ( $P$-value $\left.<0.05\right)$ between groups according to Tukey's test. 2***: $P<0.0001$

Regarding the subject, DA levels shown by students in both subjects were similar. On the contrary, SA levels in Economics were significantly higher than in Genetics. Differences were not found when considering language as a medium of instruction in both courses, but they were present when considering only the Genetics course, where DA level was higher in the English group (Table 1). One of the factors that can influence student approach to learning is language competency [24], [78]. In some cases, when a subject is taught in English for students with a different mother tongue, deep approach can raise [48], which supports that language, direct or indirectly, is one of the factors that affects students' approaches to learning. Differences were observed in SA regarding gender. Gender is not a factor that vary student approach to learning as reported in other studies [32], [79], although in distance education differences between gender have been reported in some cases [80], [81].

Results were also studied for the secondary factors of the R-SPQ-2F questionnaire [5] (Table 2). Consequently, with results above, values of Deep Motivation (DM) and Deep Strategy (DS) were higher than the ones of Surface Motivation (SM) and Surface Strategy (SS). The comparison between subjects led to significant differences in all secondary factors but the one of DM. No differences were found when considering language neither in the general sample nor when focusing by subjects, except from the values of DS in the Genetics course, where students of the English group showed a higher level. In relation to gender, no differences were observed but for the SM levels, where females showed lower levels than males (Table 2).

Comparing results on a per student basis (Figure 1) only 3 out of 76 showed a higher SA than a DA. Although some individuals showed a common approach in both subjects, differences were observed in most of the students (Figure 1). Several factors affect the student approach to learning and can be classified as contextual, perceived, or student factors [13], [27]. Student approach is not considered a stable psychological trait [60], [82] and can change between different subjects and years [39]. In our case, no big differences were observed between both subjects, although some students varied their approach, indicating an influence of contextual or perceived factors. 
Table 2. Values (average and standard error) of the R-SPQ-2F questionnaire scales in the deep motivation (DM), deep strategy (DS), surface motivation (SM) and surface strategy (SS) for subject (General Genetics, $G G$, and Biotechnology Business Economics, BBE), language used as medium of instruction and gender.

\begin{tabular}{|c|c|c|c|c|c|c|c|c|}
\hline & $D M^{1}$ & & DS & & $S M$ & & SS & \\
\hline \multicolumn{9}{|l|}{ Subject } \\
\hline GG & $3.40 \pm 0.05$ & $a^{1}$ & $3.41 \pm 0.06$ & $b$ & $1.46 \pm 0.04$ & a & $2.12 \pm 0.05$ & $a$ \\
\hline BBE & $3.38 \pm 0.07$ & $\mathrm{a}$ & $3.16 \pm 0.07$ & a & $1.65 \pm 0.06$ & $b$ & $2.33 \pm 0.06$ & $\mathrm{~b}$ \\
\hline \multicolumn{9}{|l|}{ Language } \\
\hline Spanish & $3.36 \pm 0.05$ & $a$ & $3.29 \pm 0.06$ & a & $1.57 \pm 0.04$ & $a$ & $2.24 \pm 0.05$ & a \\
\hline English & $3.44 \pm 0.07$ & $a$ & $3.31 \pm 0.08$ & a & $1.50 \pm 0.05$ & $a$ & $2.17 \pm 0.07$ & a \\
\hline GG Spanish & $3.34 \pm 0.06$ & $\mathrm{a}$ & $3.32 \pm 0.07$ & a & $1.49 \pm 0.05$ & a & $2.16 \pm 0.07$ & a \\
\hline GG English & $3.49 \pm 0.09$ & $a$ & $3.58 \pm 0.10$ & $b$ & $1.42 \pm 0.07$ & a & $2.06 \pm 0.08$ & a \\
\hline BBE Spanish & $3.39 \pm 0.09$ & $\mathrm{a}$ & $3.26 \pm 0.09$ & a & $1.70 \pm 0.08$ & a & $2.37 \pm 0.08$ & a \\
\hline BBE English & $3.38 \pm 0.10$ & a & $3.03 \pm 0.11$ & a & $1.58 \pm 0.08$ & a & $2.28 \pm 0.10$ & a \\
\hline \multicolumn{9}{|l|}{ Gender } \\
\hline Female & $3.38 \pm 0.06$ & $a$ & $3.31 \pm 0.06$ & $a$ & $1.48 \pm 0.04$ & $a$ & $2.16 \pm 0.05$ & a \\
\hline Male & $3.41 \pm 0.06$ & a & $3.28 \pm 0.08$ & a & $1.67 \pm 0.05$ & $\mathrm{~b}$ & $2.31 \pm 0.06$ & a \\
\hline Total & $3.39 \pm 0.04$ & & $3.30 \pm 0.05$ & & $1.54 \pm 0.03$ & & $2.21 \pm 0.04$ & \\
\hline
\end{tabular}

${ }^{1}$ Different letters in the same column indicate significant differences $(P$-value $<0.05)$ between groups according to Tukey's test.

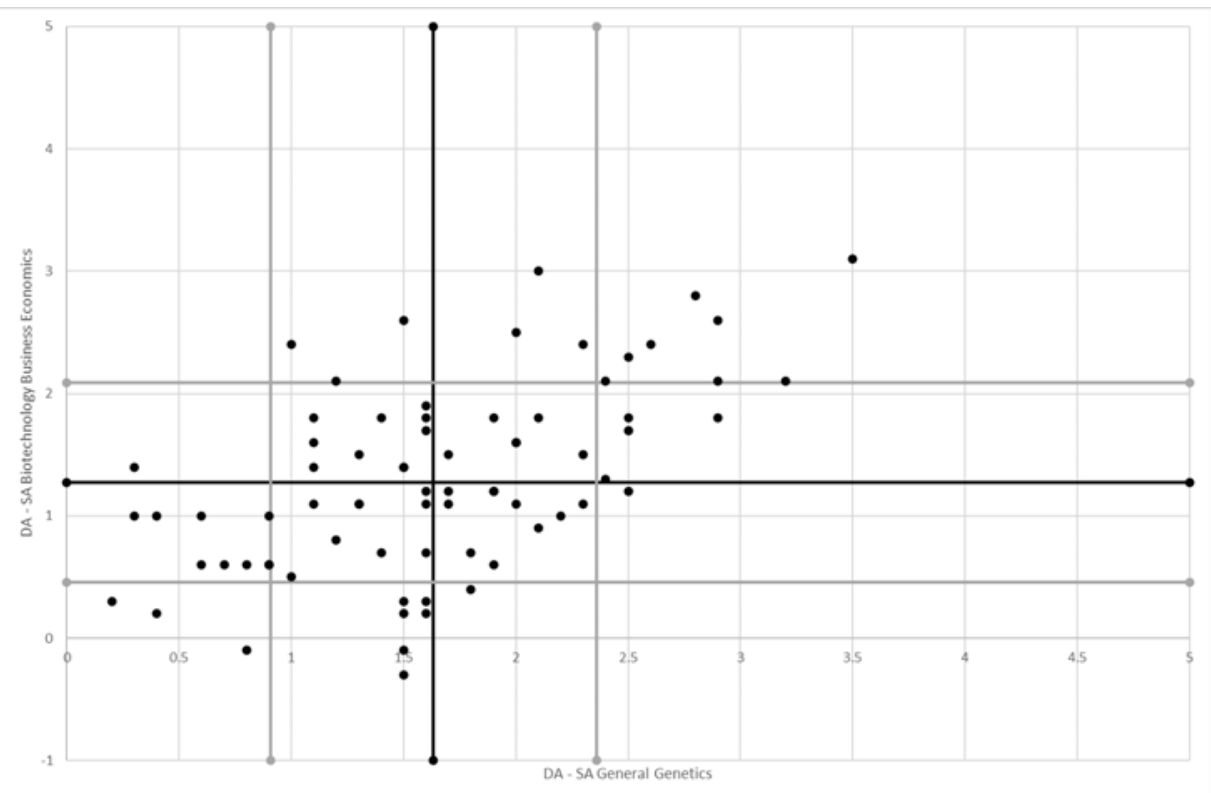

Figure 1. Deep approach (DA) minus surface approach (SA) distribution of scores for each common student of General Genetics and Biotechnology Business Economics subjects. The black lines depict mean values for DA and SA and the grey lines the mean plus or minus the standard deviation.

Studying the different correlations that affect the subdivision of DA and SA, significant relations were detected (Table 3). High and positive correlations were observed between DA and DM and DS, as well as between SA and SM and SS. As expected, significant negative correlations between DA and SA and their corresponding strategies and motivations were shown. Other studies showed a similar result [72], [83], [84], as the work of Biggs et al. [5] predicted. 
Table 3. Correlations between different factor of the R-SPQ-2F questionnaire scales. Deep approach (DA), surface approach (SA), deep motivation (DM), deep strategy (DS), surface motivation (SM) and surface strategy (SS).

\begin{tabular}{lccccc} 
& $D A$ & $S A$ & $D M$ & $D S$ & $S M$ \\
\hline$S A$ & $-0.30^{* * *}$ & & & & \\
$D M$ & $0.89^{* * *}$ & $-0.26^{* * *}$ & & & \\
$D S$ & $0.91^{* * *}$ & $-0.27^{* * *}$ & $0.62^{* * *}$ & & \\
$S M$ & $-0.19^{*}$ & $0.86^{* * *}$ & $-0.19^{*}$ & $-0.15^{*}$ & \\
$S S$ & $-0.32^{* * *}$ & $0.92^{* * *}$ & $-0.26^{* * *}$ & $-0.31^{* * *}$ & $0.59 * * *$ \\
\hline${ }^{* * *}: P<0.0001,{ }^{*} 0.01<P<0.001$ & & &
\end{tabular}

The internal consistency of the questionnaire was evaluated by the Cronbach's alpha (Table 4). Obtained values are close or higher than 0.7 in the main factors and showed lower levels in the secondary factors, mainly in SM and SS. Results in the same pattern were observed in other studies [19], [21], [71], [72], [84], [85], indicating that the questionnaire has a strong association with the two main factors, but lower for the secondary factors.

Table 4. Cronbach alpha coefficient values (95\% lower confidence band) among the different R-SPQ-2F questionnaire scales of the questionnaires evaluated. Deep approach (DA), surface approach (SA), deep motivation (DM), deep strategy (DS), surface motivation (SM), and surface strategy (SS) for subject (General Genetics, GG, and Biotechnology Business Economics, BBE), language used as medium of instruction and gender.

\begin{tabular}{lcccccc}
\hline & $D A$ & $S A$ & $D M$ & $D S$ & $S M$ & $S S$ \\
\hline $\begin{array}{l}\text { Subject } \\
\text { GG }\end{array}$ & $0.72(0.66)$ & $0.62(0.55)$ & $0.39(0.27)$ & $0.67(0.60)$ & $0.37(0.24)$ & $0.44(0.32)$ \\
BBE & $0.78(0.74)$ & $0.74(0.69)$ & $0.62(0.55)$ & $0.63(0.56)$ & $0.59(0.50)$ & $0.57(0.48)$ \\
\hline Language & & & & & & \\
Spanish & $0.72(0.67)$ & $0.67(0.67)$ & $0.67(0.61)$ & $0.61(0.46)$ & $0.46(0.35)$ & $0.35(0.62)$ \\
English & $0.78(0.74)$ & $0.74(0.72)$ & $0.72(0.67)$ & $0.67(0.55)$ & $0.55(0.46)$ & $0.46(0.72)$ \\
GG Spanish & $0.68(0.62)$ & $0.63(0.56)$ & $0.32(0.18)$ & $0.62(0.54)$ & $0.33(0.19)$ & $0.41(0.29)$ \\
GG English & $0.76(0.72)$ & $0.59(0.51)$ & $0.55(0.45)$ & $0.72(0.66)$ & $0.48(0.37)$ & $0.49(0.38)$ \\
BBE Spanish & $0.78(0.74)$ & $0.69(0.63)$ & $0.65(0.58)$ & $0.63(0.56)$ & $0.60(0.51)$ & $0.50(0.40)$ \\
BBE English & $0.78(0.74)$ & $0.78(0.74)$ & $0.61(0.53)$ & $0.62(0.54)$ & $0.58(0.49)$ & $0.64(0.57)$ \\
\hline Gender & & & & & & \\
Female & $0.79(0.74)$ & $0.73(0.68)$ & $0.61(0.53)$ & $0.67(0.60)$ & $0.58(0.49)$ & $0.55(0.46)$ \\
Male & $0.63(0.56)$ & $0.52(0.43)$ & $0.11(-0.08)$ & $0.66(0.59)$ & $0.21(0.05)$ & $0.43(0.31)$ \\
\hline Total & $0.75(0.70)$ & $0.69(0.63)$ & $0.50(0.39)$ & $0.66(0.59)$ & $0.51(0.40)$ & $0.51(0.41)$ \\
\hline
\end{tabular}

\section{CONCLUSIONS}

Being aware of the learning approach of students is a powerful instrument for teachers to address their courses. Both personal and environmental factors have been proved significant in the way students engage with the subject. This study has analyzed the learning approach of the same group of students in two different moments of the same academic year, using the R-SPQ-2F questionnaire developed by Biggs et al. [5]. Each of the measures has been made in a different context, within the frame of a Genetics subject in first place and in an Economics subject, later. Results showed higher levels of Deep Approach in both subjects rather than Surface Approach, although some of the factors also proved significantly different between the subjects, being higher in the Genetics course. The influence of the course or the term remains as a studying factor for future research. 
Data gathered in the study pointed to the fact that students adopt a strategy and can vary their learning approach according to the context and the requirements of the course. Further analyses should be carried out to be able to identify the elements of the context that enable the activation of the DA and DM.

\section{ACKNOWLEDGEMENTS}

The publication of this work has been funded by a project of Educational Improvement and Innovation awarded by the Vice Dean for Studies, Quality and Accreditation of the Universitat Politècnica de València (Spain).

\section{REFERENCES}

[1] A. S. Koster and J. D. Vermunt, "Longitudinal Changes of Deep and Surface Learning in a Constructivist Pharmacy Curriculum," Pharmacy, vol. 8, no. 4, p. 200, Oct. 2020, doi: 10.3390/pharmacy8040200.

[2] R. Edwards, "Policy and professionalism in pharmacy education," Pharm. Educ., vol. 11, no. 1, pp. 209-211, 2011.

[3] H. Asikainen and D. Gijbels, "Do Students Develop Towards More Deep Approaches to Learning During Studies? A Systematic Review on the Development of Students' Deep and Surface Approaches to Learning in Higher Education," Educ. Psychol. Rev., vol. 29, no. 2, pp. 205-234, Jun. 2017, doi: 10.1007/s10648-017-9406-6.

[4] C. Phanudulkitti, K. B. Farris, P. Makmee, and T. Kittisopee, "Deep approach to learning of pharmacy students: A multilevel analysis," Pharm. Educ., vol. 18, no. 1, pp. 99-109, 2018.

[5] J. Biggs, D. Kember, and D. Y. P. Leung, "The revised two-factor Study Process Questionnaire: RSPQ-2F," Br. J. Educ. Psychol., vol. 71, no. 1, pp. 133-149, Mar. 2001, doi: 10.1348/000709901158433.

[6] N. Entwistle and D. Entwistle, "Preparing for examinations: The interplay of memorising and understanding, and the development of knowledge objects," High. Educ. Res. Dev., vol. 22, no. 1, pp. 19-41, 2003, doi: 10.1080/0729436032000056562.

[7] D. Kember, J. Biggs, and D. Y. P. Leung, "Examining the multidimensionality of approaches to learning through the development of a revised version of the Learning Process Questionnaire," $\mathrm{Br}$. J. Educ. Psychol., vol. 74, no. 2, pp. 261-279, Jun. 2004, doi: 10.1348/000709904773839879.

[8] L. K. Fryer, "Building Bridges: Seeking Structure and Direction for Higher Education Motivated Learning Strategy Models," Educ. Psychol. Rev., vol. 29, no. 2, pp. 325-344, Jun. 2017, doi: 10.1007/s10648-017-9405-7.

[9] F. Marton and R. Säljö, "On qualitative differences in learning: I-Outcome and process," Br. J. Educ. Psychol., vol. 46, no. 1, pp. 4-11, Feb. 1976, doi: 10.1111/j.2044-8279.1976.tb02980.x.

[10] F. Marton and R. Säljö, "On qualitative differences in learning-Il outcome as a function of the learners's conception of the task," Br. J. Educ. Psychol., vol. 46, no. 2, pp. 115-127, Jun. 1976, doi: 10.1111/j.2044-8279.1976.tb02304.x.

[11] N. ENTWISTLE and S. WATERSTON, "APPROACHES TO STUDYING AND LEVELS OF PROCESSING IN UNIVERSITY STUDENTS," Br. J. Educ. Psychol., vol. 58, no. 3, pp. 258-265, Nov. 1988, doi: 10.1111/j.2044-8279.1988.tb00901.x.

[12] N. Entwistle, V. McCune, and J. Hounsell, "Approaches to Studying and Perceptions of University Teaching-Learning Environments: Concepts, Measures and Preliminary Findings," Edinburgh, 2002. doi: $10.13140 / R G .2 .2 .33594 .80329$.

[13] J. Biggs, Student Approaches to Learning and Studying. Research Monograph. Melbourne: Australian Council Educational Research (ACER), 1987.

[14] J. Biggs and C. Tang, Teaching for quality learning at university. (4th Edn.), 4th editio. Berkshire: Open University Press McGraw-Hill, 2011. 
[15] Y. F. Zakariya, K. Bjørkestøl, H. K. Nilsen, S. Goodchild, and M. Lorås, "University students' learning approaches: An adaptation of the revised two-factor study process questionnaire to Norwegian," Stud. Educ. Eval., vol. 64, no. May 2019, p. 100816, Mar. 2020, doi: 10.1016/ j.stueduc.2019.100816.

[16] A. Stes, S. De Maeyer, and P. Van Petegem, "Examining the Cross-Cultural Sensitivity of the Revised Two-Factor Study Process Questionnaire (R-SPQ-2F) and Validation of a Dutch Version," PLoS One, vol. 8, no. 1, p. e54099, Jan. 2013, doi: 10.1371/journal.pone.0054099.

[17] G. Vanthournout, L. Coertjens, D. Gijbels, V. Donche, and P. Van Petegem, "Assessing students' development in learning approaches according to initial learning profiles: A person-oriented perspective," Stud. Educ. Eval., vol. 39, no. 1, pp. 33-40, Mar. 2013, doi: 10.1016/ j.stueduc.2012.08.002.

[18] G. Webb, "Deconstructing deep and surface: Towards a critique of phenomenography," High. Educ., vol. 33, no. 2, pp. 195-212, 1997, doi: 10.1023/A:1002905027633.

[19] Y. Salamonson et al., "Learning approaches as predictors of academic performance in first year health and science students," Nurse Educ. Today, vol. 33, no. 7, pp. 729-733, Jul. 2013, doi: 10.1016/j.nedt.2013.01.013.

[20] K. Trigwell and M. Prosser, "Improving the quality of student learning: the influence of learning context and student approaches to learning on learning outcomes," in Higher Eduation, no. 22, 1991, pp. 251-266.

[21] B. Vaughan, "A Rasch analysis of the Revised Study Process Questionnaire in an Australian osteopathy student cohort," Stud. Educ. Eval., vol. 56, no. December, pp. 144-153, 2018, doi: 10.1016/j.stueduc.2017.12.003.

[22] W. May, E.-K. Chung, D. Elliott, and D. Fisher, "The relationship between medical students' learning approaches and performance on a summative high-stakes clinical performance examination," Med. Teach., vol. 34, no. 4, pp. e236-e241, Apr. 2012, doi: 10.3109/ 0142159X.2012.652995.

[23] C. K. F. Mok, B. Dodd, and T. L. Whitehill, "Speech-language pathology students' approaches to learning in a problem-based learning curriculum," Int. J. Speech. Lang. Pathol., vol. 11, no. 6, pp. 472-481, Jan. 2009, doi: 10.3109/17549500903003052.

[24] N. Dong, M. Bai, H. Zhang, and J. Zhang, "Approaches to learning IFRS by Chinese accounting students," J. Account. Educ., vol. 48, pp. 1-11, Sep. 2019, doi: 10.1016/j.jaccedu.2019.04.002.

[25] P. Zeegers, "Approaches to learning in science: A longitudinal study," Br. J. Educ. Psychol., vol. 71, no. 1, pp. 115-132, Mar. 2001, doi: 10.1348/000709901158424.

[26] J. B. Biggs, "From Theory to Practice: A Cognitive Systems Approach," High. Educ. Res. Dev., vol. 12, no. 1, pp. 73-85, 1993, doi: 10.1080/0729436930120107.

[27] M. Baeten, E. Kyndt, K. Struyven, and F. Dochy, "Using student-centred learning environments to stimulate deep approaches to learning: Factors encouraging or discouraging their effectiveness," Educ. Res. Rev., vol. 5, no. 3, pp. 243-260, Jan. 2010, doi: 10.1016/j.edurev.2010.06.001.

[28] Q. Xie and L. fang Zhang, "Demographic Factors, Personality, and Ability as Predictors of Learning Approaches," Asia-Pacific Educ. Res., vol. 24, no. 4, pp. 569-577, 2015, doi: 10.1007/s40299-0140202-5.

[29] D. Gijbels, G. Van de Watering, F. Dochy, and P. Van den Bossche, "The relationship between students' approaches to learning and the assessment of learning outcomes," Eur. J. Psychol. Educ., vol. 20, no. 4, pp. 327-341, Dec. 2005, doi: 10.1007/BF03173560.

[30] R. Z. Elias, "Students' Approaches to Study in Introductory Accounting Courses," J. Educ. Bus., vol. 80, no. 4, pp. 194-199, Mar. 2005, doi: 10.3200/JOEB.80.4.194-199.

[31] P. Everaert, E. Opdecam, and S. Maussen, "The relationship between motivation, learning approaches, academic performance and time spent," Account. Educ., vol. 26, no. 1, pp. 78-107, Jan. 2017, doi: 10.1080/09639284.2016.1274911.

[32] J. T. E. Richardson, "Approaches to studying across the adult life span: Evidence from distance education," Learn. Individ. Differ., vol. 26, pp. 74-80, Aug. 2013, doi: 10.1016/j.lindif.2013.04.012. 
[33] L. Gow and D. Kember, "Does higher education promote independent learning?," High. Educ., vol. 19, no. 3, pp. 307-322, 1990, doi: 10.1007/BF00133895.

[34] J. T. E. Richardson and E. King, "Adult Students in Higher Education: Burden or Boon?," J. Higher Educ., vol. 69, no. 1, p. 65, Jan. 1998, doi: 10.2307/2649182.

[35] G. Harper and D. Kember, "Approaches to Study of Distance Education Students," Br. J. Educ. Technol., vol. 17, no. 3, pp. 212-222, Oct. 1986, doi: 10.1111/j.1467-8535.1986.tb00510.x.

[36] M. G. Eley, "Differential adoption of study approaches within individual students," High. Educ., vol. 23, no. 3, pp. 231-254, Apr. 1992, doi: 10.1007/BF00145015.

[37] G. Piumatti, M. Abbiati, M. W. Gerbase, and A. Baroffio, "Patterns of Change in Approaches to Learning and Their Impact on Academic Performance Among Medical Students: Longitudinal Analysis," Teach. Learn. Med., vol. 0, no. 0, pp. 1-11, Oct. 2020, doi: 10.1080/10401334.2020.1814295.

[38] J. Nieminen, S. Lindblom-Ylänne, and K. Lonka, "The Development of Study Orientations and Study Success in Students of Pharmacy," Instr. Sci., vol. 32, no. 5, pp. 387-417, Sep. 2004, doi: 10.1023/B:TRUC.0000044642.35553.e5.

[39] M. Leiva-Brondo et al., "Study Approaches of Life Science Students Using the Revised Two-Factor Study Process Questionnaire (R-SPQ-2F)," Educ. Sci., vol. 10, no. 7, p. 173, Jun. 2020, doi: 10.3390/educsci10070173.

[40] M. Prosser and K. Trigwell, Understanding learning and leaching. The experience in higher education. Buckingham: Open University Press, 1999.

[41] P. Lietz and B. Matthews, "The Effects of College Students' Personal Values on Changes in Learning Approaches," Res. High. Educ., vol. 51, no. 1, pp. 65-87, Feb. 2010, doi: 10.1007/s11162009-9147-6.

[42] J. Wilding and B. Andrews, "Life goals, approaches to study and performance in an undergraduate cohort," Br. J. Educ. Psychol., vol. 76, no. 1, pp. 171-182, Mar. 2006, doi: 10.1348/000709904X24726.

[43] P. Zeegers, "Student learning in higher education: a path analysis of academic achievement in science," High. Educ. Res. Dev., vol. 23, no. 1, pp. 35-56, Feb. 2004, doi: 10.1080/0729436032000168487.

[44] L. Rodriguez and F. Cano, "The learning approaches and epistemological beliefs of university students: a cross-sectional and longitudinal study," Stud. High. Educ., vol. 32, no. 5, pp. 647-667, Oct. 2007, doi: 10.1080/03075070701573807.

[45] J. A. Ballantine, A. Duff, and P. McCourt Larres, "Accounting and business students' approaches to learning: A longitudinal study,” J. Account. Educ., vol. 26, no. 4, pp. 188-201, Dec. 2008, doi: 10.1016/j.jaccedu.2009.03.001.

[46] M. Hall, A. Ramsay, and J. Raven, "Changing the learning environment to promote deep learning approaches in first-year accounting students," Account. Educ., vol. 13, no. 4, pp. 489-505, Dec. 2004, doi: 10.1080/0963928042000306837.

[47] C. Gordon and R. Debus, "Developing deep learning approaches and personal teaching efficacy within a preservice teacher education context," Br. J. Educ. Psychol., vol. 72, no. 4, pp. 483-511, 2002, doi: 10.1348/00070990260377488.

[48] J. S. Jeong, D. González-gómez, M. C. Conde-núñez, and A. Gallego-picó, "Examination of students ' engagement with R-SPQ- $2 \mathrm{~F}$ of learning approach in flipped sustainable science course," J. Balt. Sci. Educ., vol. 18, no. 6, pp. 880-891, 2019, [Online]. Available: http://www.scientiasocialis.lt/jbse/?q=node/811.

[49] N. J. Entwistle and H. Tait, "Approaches to learning, evalutions of teaching, and perferences for contrasting academic environments," High. Eduation, vol. 19, no. 2, pp. 291-299, 1990.

[50] S. F. Leung, E. Mok, and D. Wong, "The impact of assessment methods on the learning of nursing students," Nurse Educ. Today, vol. 28, no. 6, pp. 711-719, Aug. 2008, doi:

10.1016/j.nedt.2007.11.004. 
[51] J. Biggs, "What the Student Does: teaching for enhanced learning," High. Educ. Res. Dev., vol. 18, no. 1, pp. 57-75, Apr. 1999, doi: 10.1080/0729436990180105.

[52] D. Gijbels, L. Coertjens, G. Vanthournout, E. Struyf, and P. Van Petegem, "Changing students' approaches to learning: a two-year study within a university teacher training course," Educ. Stud., vol. 35, no. 5, pp. 503-513, Dec. 2009, doi: 10.1080/03055690902879184.

[53] K. Trigwell, M. Prosser, and F. Waterhouse, "Relations between teachers' approaches to teaching and students' approaches to learning," High. Educ., vol. 37, no. 1, pp. 57-70, 1999, doi: 10.1023/A:1003548313194.

[54] S. E. Volet, P. D. Renshaw, and K. Tietzel, "A short-term longitudinal investigation of cross-cultural differences in study approaches using Biggs' SPQ questionnaire," Br. J. Educ. Psychol., vol. 64, no. 2, pp. 301-318, Jun. 1994, doi: 10.1111/j.2044-8279.1994.tb01104.x.

[55] B. Vaughan, "Confirmatory factor analysis of the Study Process Questionnaire in an Australian osteopathy student population," Int. J. Osteopath. Med., vol. 20, pp. 62-67, 2016, doi: 10.1016/j.ijosm.2016.03.001.

[56] F. Justicia, M. C. Pichardo, F. Cano, A. B. G. Berbén, and J. De la Fuente, "The Revised TwoFactor Study Process Questionnaire (R-SPQ-2F): Exploratory and confirmatory factor analyses at item level," Eur. J. Psychol. Educ., vol. 23, no. 3, pp. 355-372, Sep. 2008, doi: 10.1007/BF03173004.

[57] D. Kember, M. Charlesworth, H. Davies, J. McKay, and V. Stott, "Evaluating the effectiveness of educational innovations: Using the study process questionnaire to show that meaningful learning occurs," Stud. Educ. Eval., vol. 23, no. 2, pp. 141-157, Jan. 1997, doi: 10.1016/S0191491X(97)00009-6.

[58] M. Prosser and K. Trigwell, "Qualitative variation in approaches to university teaching and learning in large first-year classes," High. Educ., vol. 67, no. 6, pp. 783-795, 2014, doi: 10.1007/s10734013-9690-0.

[59] K. Wilson and J. Fowler, "Assessing the impact of learning environments on students' approaches to learning: comparing conventional and action learning designs," Assess. Eval. High. Educ., vol. 30, no. 1, pp. 87-101, Feb. 2005, doi: 10.1080/0260293042003251770.

[60] K. Struyven, F. Dochy, S. Janssens, and S. Gielen, "On the dynamics of students' approaches to learning: The effects of the teaching/learning environment," Learn. Instr., vol. 16, no. 4, pp. 279294, 2006, doi: 10.1016/j.learninstruc.2006.07.001.

[61] D. KEMBER and L. GOW, "Cultural specificty of approaches to study," Br. J. Educ. Psychol., vol. 60, no. 3, pp. 356-363, Nov. 1990, doi: 10.1111/j.2044-8279.1990.tb00952.x.

[62] W. B. Michael, J. J. Michael, and W. S. Zimmerman, Study Attitudes and Methods Survey (SAMS). San Diego, CA: Educational and Industrial Testing Service, 1985.

[63] R. R. Schmeck, F. Ribich, and N. Ramanaiah, "Development of a Self-Report Inventory for Assessing Individual Differences in Learning Processes," Appl. Psychol. Meas., vol. 1, no. 3, pp. 413-431, Jun. 1977, doi: 10.1177/014662167700100310.

[64] N. J. Entwistle and H. Tait, The revised approaches to studying inventory. Edinburgh, Scotland: Centre for Research on Learning and Instruction, 1995.

[65] H. Tait, N. J. Entwistle, and V. McCune, "ASSIST: a reconceptualisation of the Approaches to Studying Inventory," in Improving students as learners, C. Rust, Ed. Oxford: Oxford Brookes University, The Oxford Centre for Staff and Learning Development., 1998, pp. 262-271.

[66] N. Entwistle and T. Hilary, "Approaches and Study Skills Inventory for Students (ASSIST) (incorporating the Revised Approaches to Studying Inventory - RASI)," 2013, [Online]. Available: https://www.researchgate.net/publication/260291730_Approaches_and_Study_Skills_Inventory_f or_Students_ASSIST_incorporating_the_Revised_Approaches_to_Studying_Inventory_-_RASI.

[67] C. E. Weinstein, Learning and Study Strategies Inventory. Clearwater, FL: H \& H Publishing, 1987.

[68] J. D. Vermunt, Inventory of Learning Styles in Higher Education: Scoring key. Tilburg, The Netherlands: Tilburg University, Department of Educational Psychology, 1994. 
[69] D. Kember and D. Y. P. Leung, "The dimensionality of approaches to learning: an investigation with confirmatory factor analysis on the structure of the SPQ and LPQ," Br. J. Educ. Psychol., vol. 68, no. 3, pp. 395-407, Sep. 1998, doi: 10.1111/j.2044-8279.1998.tb01300.x.

[70] D. Kember, "MISCONCEPTIONS ABOUT THE LEARNING APPROACHES, MOTIVATION AND STUDY PRACTICES OF ASIAN STUDENTS," in The RoutledgeFalmer Reader in Higher Education, vol. 40, no. 1, Abingdon, UK: Taylor \& Francis, 2000, pp. 37-55.

[71] M. López-Aguado and L. Gutiérrez-Provecho, "Checking the underlying structure of R-SPQ-2F using covariance structure analysis," Cult. y Educ., vol. 30, no. 1, pp. 105-141, 2018, doi: 10.1080/11356405.2017.1416787.

[72] A. Socha and E. A. Sigler, "Exploring and 'reconciling' the factor structure for the Revised Twofactor Study Process Questionnaire," Learn. Individ. Differ., vol. 31, pp. 43-50, Apr. 2014, doi: 10.1016/j.lindif.2013.12.010.

[73] L. K. Fryer, P. Ginns, R. A. Walker, and K. Nakao, "The adaptation and validation of the CEQ and the R-SPQ-2F to the Japanese tertiary environment," Br. J. Educ. Psychol., vol. 82, no. 4, pp. 549563, Dec. 2012, doi: 10.1111/j.2044-8279.2011.02045.x.

[74] Y. M. Chan and C. M. S. Chan, "Approach to Learning of Sub-Degree Students in Hong Kong," Res. Educ., vol. 84, no. 1, pp. 65-78, Nov. 2010, doi: 10.7227/RIE.84.5.

[75] J. M. Weller, M. Henning, N. Civil, L. Lavery, M. J. Boyd, and B. Jolly, "Approaches to learning for the ANZCA Final Examination and validation of the revised Study Process Questionnaire in specialist medical training," Anaesth. Intensive Care, vol. 41, no. 5, pp. 631-640, 2013, doi: 10.1177/0310057x1304100509.

[76] Q. Xie, "Validating the Revised Two-Factor Study Process Questionnaire among Chinese University Students," Int. J. Educ. Psychol., vol. 16, no. 1, pp. 4-19, 2014.

[77] I. Muñoz San Roque, L. Prieto Navarro, and J. C. Torre Puente, "Enfoques de aprendizaje, autorregulación, autoeficacia, competencias y evaluación. Un estudio descriptivo de estudiantes de educación infantil y primaria," in Educación y nuevas sociedades, J. C. Torre Puente, Ed. Madrid: Universidad Pontificia Comillas, 2012, pp. 237-266.

[78] B. J. Bobe and B. J. Cooper, "The effect of language proficiency on approaches to learning and satisfaction of undergraduate accounting students," Account. Educ., vol. 28, no. 2, pp. 149-171, Mar. 2017, doi: 10.1080/09639284.2017.1396481.

[79] J. D. Vermunt, "Relations between student learning patterns and personal and contextual factors and academic performance," High. Educ., vol. 49, no. 3, pp. 205-234, Apr. 2005, doi: 10.1007/s10734-004-6664-2.

[80] M. Rubin, J. Scevak, E. Southgate, S. MacQueen, P. Williams, and H. Douglas, "Older Women, Deeper Learning, and Greater Satisfaction at University: Age and Gender Predict University Students' Learning Approach and Degree Satisfaction," J. Divers. High. Educ., vol. 11, no. 1, pp. 82-96, 2018, doi: 10.1037/dhe0000042.

[81] J. T. E. Richardson, "Perceptions of academic quality and approaches to studying among technology students in distance education," Eur. J. Eng. Educ., vol. 31, no. 4, pp. 421-433, Aug. 2006, doi: 10.1080/03043790600676307.

[82] J. Nijhuis, M. Segers, and W. Gijselaers, "The extent of variability in learning strategies and students' perceptions of the learning environment," Learn. Instr., vol. 18, no. 2, pp. 121-134, Apr. 2008, doi: 10.1016/j.learninstruc.2007.01.009.

[83] D. Y. P. Leung, P. Ginns, and D. Kember, "Examining the Cultural Specificity of Approaches To Learning in Universities in Hong Kong and Sydney," J. Cross. Cult. Psychol., vol. 39, no. 3, pp. 251266, May 2008, doi: 10.1177/0022022107313905.

[84] J. C. Immekus and P. K. Imbrie, "A Test and Cross-Validation of the Revised Two-Factor Study Process Questionnaire Factor Structure Among Western University Students," Educ. Psychol. Meas., vol. 70, no. 3, pp. 495-510, Jun. 2010, doi: 10.1177/0013164409355685.

[85] J. Zhao, Y. Yang, K. Zhang, J. Jeong, Z. Zeng, and H. Zang, "Does crop rotation yield more in China? A meta-analysis," F. Crop. Res., vol. 245, no. September 2019, p. 107659, 2020, doi: 10.1016/j.fcr.2019.107659. 